\title{
Efficacy and reinfection with soil-transmitted helminths 18-weeks post-treatment with albendazole-ivermectin, albendazole- mebendazole, albendazole-oxantel pamoate and mebendazole
}

\author{
Benjamin Speich ${ }^{1,2+}$, Wendelin Moser ${ }^{1,2+}$, Said M. Ali ${ }^{3}$, Shaali M. Ame ${ }^{3}$, Marco Albonico ${ }^{4}$, Jan Hattendorf ${ }^{2,5}$
} and Jennifer Keiser ${ }^{1,2^{*}}$

\begin{abstract}
Background: Preventive chemotherapy with albendazole or mebendazole is the current strategy to control soiltransmitted helminth (STH) infections (i.e. Ascaris lumbricoides, hookworm and Trichuris trichiura). STH reinfections, in particular A. lumbricoides and T. trichiura occur rapidly after treatment with the standard drugs. However, their low efficacy against T. trichiura, made an accurate assessment of reinfection patterns impossible.

Methods: In 2013 a randomised controlled trial was conducted on Pemba Island, Tanzania. School-aged children diagnosed positive for T. trichiura, were randomly allocated to (i) albendazole-ivermectin; (ii) albendazole-mebendazole; (iii) albendazole-oxantel pamoate; or (iv) mebendazole. Here we report the efficacy [cure rates (CR) and egg-reduction rates (ERR)], reinfection rates and new infections determined 18 weeks post-treatment.

Results: For a total of 405 children complete baseline and follow-up data were available. Similar to the efficacy determined after 3 weeks, 18 weeks after treatment albendazole-oxantel pamoate showed a significantly higher efficacy against T. trichiura (CR: 54.0 \%, 95 \% Cl: 43.7-64.0; ERR: 98.6 \%, 95 \% Cl: 97.8-99.2) compared to the other treatment arms. Children treated with albendazole-oxantel pamoate or albendazole-ivermectin had fewer moderate infections compared to children treated with albendazole. The reinfection rates 18 weeks post-treatment among all treatment arms were 37.2 \% for T. trichiura (95 \% Cl: 28.3-46.8), 34.6\% for A. lumbricoides (95 \% Cl: 27.3-42.3) and $25.0 \%$ for hookworms (95 \% Cl: 15.5-36.6).
\end{abstract}

Conclusion: The moderate reinfection rates with STHs 18 weeks post-treatment support the concept of regular anthelminthic treatment in highly endemic settings. Combination chemotherapy might achieve decreased morbidity in children since in the albendazole plus oxantel pamoate and albendazole plus ivermectin treatment arms only few moderate $T$. trichiura infections remained. Further trials should investigate the long term efficacy of albendazole-oxantel pamoate (i.e. 6 and 12 month post-treatment) and after several rounds of treatment in order to develop recommendations for appropriate control approaches for STH infections.

Trial registration: Current Controlled Trials ISRCTN80245406

Keywords: Trichuris trichiura, Ascaris lumbricoides, Hookworm, Randomised controlled trial, Reinfection, Oxantel pamoate

\footnotetext{
* Correspondence: jennifer.keiser@unibas.ch

${ }^{\dagger}$ Equal contributors

${ }^{1}$ Department of Medical Parasitology and Infection Biology, Swiss Tropical

and Public Health Institute, Basel, Switzerland

${ }^{2}$ University of Basel, Basel, Switzerland

Full list of author information is available at the end of the article
} 


\section{Background}

The most common soil-transmitted helminths (STH; Ascaris lumbricoides, hookworms and Trichuris trichiura) infect approximately 1.5 billion people [1] worldwide with the highest prevalences in Asia and Africa. Schoolaged children living in the least developed settings, lacking clean water and sanitation facilities are primarily affected by $A$. lumbricoides and T. trichiura, while hookworm infections mostly occur in adults $[2,3]$. Untreated, chronically infected children might suffer from anemia, malnutrition and impairments in cognitive and physical development [2]. The burden of soil-transmitted helminthiasis has been estimated as 5.3 million disability-adjusted life years [1]. Large scale distribution of anthelminthic drugs without prior diagnosis ("preventive chemotherapy") mainly given to school-aged children, is the current strategy to control morbidity [4]. The most common anthelminthic drugs are albendazole and mebendazole [5]. Both drugs have high efficacy against $A$. lumbricoides, while only albendazole reveals a good performance in the treatment of hookworm infections. For the treatment of $T$. trichiura both drugs show poor cure rates in single-dose regimen [6].

Preventive chemotherapy does not avert reinfections as demonstrated in earlier studies [7, 8]. Six to 12 months after treatment with albendazole or mebendazole, the prevalence of $A$. lumbricoides reached the pretreatment level [9-11], while hookworm reinfection is slow [9]. However, it is difficult to accurately estimate the reinfection rate of $T$. trichiura since, as mentioned above, the efficacy of the benzimidazoles against $T$. trichiura is low [6], in particular when children suffer from high infection intensity [12].

In a clinical trial conducted in 2013 on Pemba Island, Tanzania, we examined the efficacy of three drug combinations (i.e. albendazole-ivermectin, albendazolemebendazole, and albendazole-oxantel pamoate) versus mebendazole against $T$. trichiura and concomitant STH infections [13]. In brief, the combination albendazoleoxantel pamoate revealed a significantly higher cure rate (CR) $(68.0 \%)$ and egg-reduction rate (ERR $99.2 \%)$ against T. trichiura than the other treatment regimens. This high efficacy might allow drawing better conclusions on reinfection with $T$. trichiura and ultimately to develop recommendations for control efforts.

The aim of the present study was to investigate whether the efficacy of albendazole-oxantel pamoate remains superior to the other combinations 18 weeks post-treatment and to monitor reinfection patterns of $T$. trichuris, A. lumbricoides and hookworms.

\section{Methods}

\section{Study oversight}

The presented data derive from a randomised controlled trial conducted among school-aged children on Pemba
Island, Tanzania [13]. Ethical clearance was obtained from the Ministry of Health and Social Welfare in Zanzibar, Tanzania (ZAMREC, reference no. 0001/June/13) and from the ethics committee of Basel, Switzerland (EKBB reference no. 123/13). The trial was registered with www.isrctn.com (identifier: ISRCTN80245406). Prior to the study start, written informed consent was obtained from the parents or legal guardians and verbal assent from the participating children.

\section{Study procedures and patients}

The clinical trial was conducted from September 2013 to January 2014. Study setting and trial procedures are presented elsewhere [13]. In brief, school-aged children diagnosed positive for $T$. trichiura were randomly assigned to one of the following treatment arms: (i) albendazole (400 mg) plus ivermectin (200 $\mu \mathrm{g} / \mathrm{kg})$; (ii) albendazole (400 mg) plus mebendazole (500 mg); (iii) albendazole $(400 \mathrm{mg})$ plus oxantel pamoate $(20 \mathrm{mg} / \mathrm{kg})$; and (iv) mebendazole (500 mg). All children were invited 3 and 18 weeks after treatment to provide stool samples on two consecutive days for the diagnosis of STH infections. Duplicate Kato-Katz thick smears were prepared from each stool sample using $41.7 \mathrm{mg}$ templates [14] and quantitatively examined by experienced laboratory technicians for eggs of $T$. trichiura, hookworms and A. lumbricoides. Slides were read under a light microscope within $60 \mathrm{~min}$ after preparation to avoid overclearing of hookworm eggs [15]. Ten percent of the Kato-Katz thick smears were randomly chosen and reexamined to assure high quality of the microscopic diagnosis [16]. In case of discrepancies, the slides were read again and discussed until consensus was reached. At the end of the study, all children remaining infected from the two schools (Mchangamdogo and Shungi) received treatment according to national guidelines [17].

\section{Statistical analysis}

Prevalence of infection with T. trichiura, A. lumbricoides and hookworms was calculated for each treatment arm at baseline, 3 and 18 weeks post-treatment for all children with a complete dataset (2 stool samples at each time point). Differences among treatment arms in CRs 3 weeks and extended CRs (extended CR: children positive at baseline and negative at both follow-ups) 18 weeks posttreatment against $T$. trichiura, $A$. lumbricoides and hookworms were assessed using logistic regression.

Geometric means (GM) for eggs per gram (EPG) were calculated by adding 1 to each count (to take the logarithm in case of EPG $=0$ ), taking the $\mathrm{GM}$ and subtracting $1\left(\mathrm{GM}=\exp \left(\left(\sum \log (\mathrm{EPG}+1)\right) / \mathrm{n}\right)-1\right)$ [18]. Bootstrap resampling method with 10,000 replicates was used for calculating the $95 \%$ confidence intervals (CI) for the ERRs. We assumed non-overlapping CI as statistical 
significant difference in ERRs. All arithmetic means (AM) are presented in the Additional file 1: Table S1.

Reinfection rates were defined as children positive at baseline, negative 3 weeks and positive 18 weeks posttreatment. New infections were defined as children negative at baseline and 3 weeks after treatment and positive 18 weeks post-treatment. As all children were by design positive for T. trichiura, new infections according to our definition, were only observed for A. lumbricoides and hookworms. Children negative at baseline and positive 3 weeks later were not included in these calculations (excluded for $A$. lumbricoides: 4 out of 405 children; and for hookworm: 27 out of 405 children).

\section{Results}

Efficacy of drug combinations against T. trichiura 3 and 18 weeks post-treatment

In total 405 children infected with $T$. trichiuria were allocated to four different treatment regimens and provided all six stool samples (i.e. duplicate stool samples at baseline, 3 and 18 weeks follow-up; Fig. 1). The efficacies 3 weeks post-treatment observed with the different treatment regimens are presented elsewhere [13] and summarised in Table 1. The CRs documented 18 weeks post-treatment were $54.0 \%$ (43.7-64.0) for albendazole-oxantel pamoate, $20.0 \%$ (12.7-29.2) for albendazole-ivermectin, $13.9 \%$ (7.8-22.2) for albendazole-mebendazole and $10.6 \%$ for mebendazole (5.4-18.1). At the second follow-up, the efficacy of the other treatment arms remained significantly lower compared to albendazole-oxantel pamoate in terms of CR ( $P$-values in Table 1$)$ and ERR (98.6, CI: 97.8-99.2) compared to the other treatments at the second follow up. Considering the arithmetic ERRs, albendazole combined with ivermectin and albendazole-oxantel pamoate were significantly higher compared to the other treatments 18 weeks post-treatment (Additional file 1: Table S1).

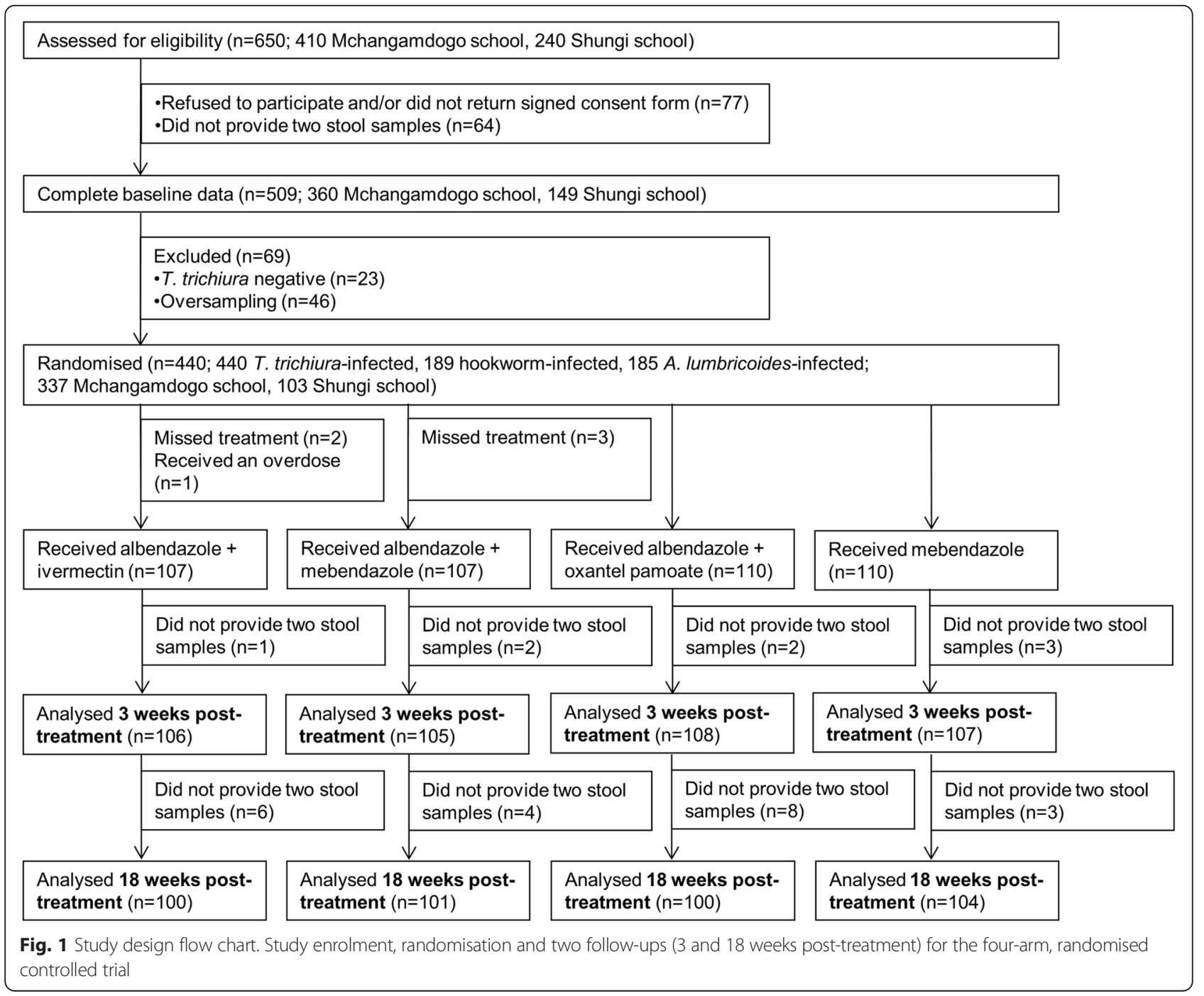


Table 1 Cure rates (CR), extended CRs, egg-reduction rates (ERR), extended ERRs and reinfection data for the four different treatments against T. trichiura infections. Results of baseline and 3 weeks follow-up have been reported elsewhere [13]

\begin{tabular}{|c|c|c|c|c|c|}
\hline \multicolumn{6}{|l|}{ Trichuris trichiura } \\
\hline & Weeks post-treatment & $\begin{array}{l}\text { Albendazole - ivermectin } \\
(n=100)\end{array}$ & $\begin{array}{l}\text { Albendazole - mebendazole } \\
(n=101)\end{array}$ & $\begin{array}{l}\text { Albendazole - oxantel pamoate } \\
(n=100)\end{array}$ & $\begin{array}{l}\text { Mebendazole } \\
(n=104)\end{array}$ \\
\hline $\begin{array}{l}\text { Children positive before } \\
\text { treatment (\%) }\end{array}$ & & $100(100)$ & $101(100)$ & $100(100)$ & $104(100)$ \\
\hline $\begin{array}{l}\text { No. of children cured } \\
(\mathrm{CR}, 95 \% \mathrm{Cl})\end{array}$ & 3 weeks & $\begin{array}{l}28 \\
(28.0,19.5-37.9, p<0.001)^{*}\end{array}$ & $\begin{array}{l}9 \\
(8.9,4.2-16.2, p<0.001)^{*}\end{array}$ & $68(68.0,57.9-77.0)$ & $\begin{array}{l}8 \\
(7.7,3.4-14.6, p<0.001)^{*}\end{array}$ \\
\hline $\begin{array}{l}\text { No. of children negative } \\
\text { (extended CR, } 95 \% \mathrm{Cl} \text { ) }\end{array}$ & 18 weeks & $\begin{array}{l}20 \\
(20.0,12.7-29.2, p<0.001)^{*}\end{array}$ & $\begin{array}{l}14 \\
(13.9,7.8-22.2, p<0.001)^{*}\end{array}$ & $54(54.0,43.7-64.0)$ & $\begin{array}{l}11 \\
(10.6,5.4-18.1, p<0.001)^{*}\end{array}$ \\
\hline \multirow[t]{3}{*}{ Geometric mean: EPG } & Baseline & 489.9 & 390.0 & 471.3 & 467.8 \\
\hline & 3 weeks & 25.0 & 176.0 & 3.7 & 207.8 \\
\hline & 18 weeks & 47.8 & 128.1 & 6.6 & 158.8 \\
\hline ERR $(95 \%$ Cl) & 3 weeks & $94.9(92.3-96.7)$ & $54.9(38.3-67.7)$ & $99.2(98.6-99.6)^{\mathrm{a}}$ & $55.6(40.0-68.0)$ \\
\hline Extended ERR (95 \% Cl) & 18 weeks & $90.2(85.3-93.6)$ & $67.2(51.9-77.9)$ & $98.6(97.8-99.2)^{a}$ & $66.1(52.0-76.6)$ \\
\hline \multirow{3}{*}{$\begin{array}{l}\text { No. of children positive } \\
\text { (prevalence, } 95 \% \mathrm{Cl} \text { ) }\end{array}$} & Baseline & $100(100,-)$ & $101(100,-)$ & $100(100,-)$ & $104(100,-)$ \\
\hline & 3 weeks & $72(72.0,62.1-80.5)$ & $92(91.1,83.8-95.8)$ & $32(32.0,23.0-42.1)$ & $96(92.3,85.4-96.6)$ \\
\hline & 18 weeks & $80(80.0,70.8-87.3)$ & $87(86.1,77.8-92.2)$ & $46(46.0,36.0-56.3)$ & $93(89.4,81.9-94.6)$ \\
\hline Reinfections (\%, $95 \%$ Cl) & 18 weeks & 15/28 (53.6, 33.9-72.5) & $2 / 9(22.2,2.8-60.0)$ & 21/68 (30.9, 20.2-43.6) & $4 / 8(50.0,15.7-84.3)$ \\
\hline
\end{tabular}

Data are $\mathrm{n}(\%, 95 \% \mathrm{Cl})$ unless otherwise indicated. EPG = egg per gram of stool. *Significantly lower CR compared to albendazole-oxantel pamoate $(P$-values derived from logistic regression)

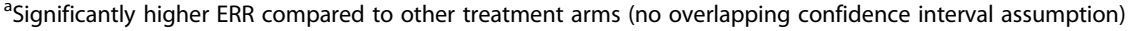


Baseline infection intensities among treatment arms were equally balanced; $70.9 \%$ of all children harboured light, $28.6 \%$ moderate and $0.5 \%$ heavy infections, stratified according to The World Health Organisation (WHO) cut-offs [18]. The number of children with light, moderate and heavy infection intensities at baseline, 3 and 18 weeks post-treatment for each treatment arm are summarised in Fig. 2. Albendazole plus ivermectin and albendazole plus oxantel pamoate caused a higher reduction of moderate $T$. trichiura infections 3 and 18 weeks post-treatment compared to albendazole-mebendazole and mebendazole. At the 18 weeks follow-up, the number of moderate infections remained higher for albendazolemebendazole $(n=16)$ and mebendazole $(n=17)$ unlike albendazole-ivermectin $(n=2)$ and albendazole-oxantel pamoate ( $n=3$; see Fig. 2 ).

\section{T. trichiura reinfection dynamics}

For $T$. trichiura the prevalence at baseline was $100 \%$ by design, as only $T$. trichiura-positive children were included $(n=405)$. In total 42 of 113 children $(37.2 \%$, 28.3-46.8), were reinfected with $T$. trichiura 18 weeks after treatment. All reinfections were of mild infection intensity (Table 1, Fig. 2).
Efficacy against $A$. lumbricoides and reinfection dynamics At baseline, 169 (41.7\%) out of 405 children were infected with A. lumbricoides. All treatment arms achieved high CRs at the first follow up (Table 2) [13]. CRs decreased for all treatment arms 18 weeks post-treatment, ranging from $60.5 \%$ for mebendazole up to $69.6 \%$ for albendazole-ivermectin. While at the first follow-up nearly all eggs were cleared (ERR 99.8-100.0\%), 18 weeks after treatment the ERRs remained significantly lower (99.0$99.2 \%)$, except for albendazole-ivermectin (99.7\%).

In total, 57 of the 165 (34.6\%; 27.3-42.3) cured children were found to be reinfected 18 weeks after being treated. Reinfections included light $(n=41)$ and moderate ( $n=16$ ) infections (Table 2, Fig. 3). In total 58 out of 232 (25.0\%; 19.7-31.1) children had acquired a new light $(n=50)$ or moderate $(n=8)$ A. lumbricoides infection.

\section{Efficacy against hookworms and reinfection dynamics}

Hookworm prevalence among the children included in the trial was $42.5 \%$ (233 of 405 children). At the second follow-up, slightly higher CRs were observed in all treatment groups compared to 3 weeks post-treatment: $54.0 \%$ for albendazole-oxantel pamoate, $53.5 \%$ for albendazolemebendazole, $50.0 \%$ for albendazole-ivermectin and $34.5 \%$ for mebendazole (Table 3). At this examination

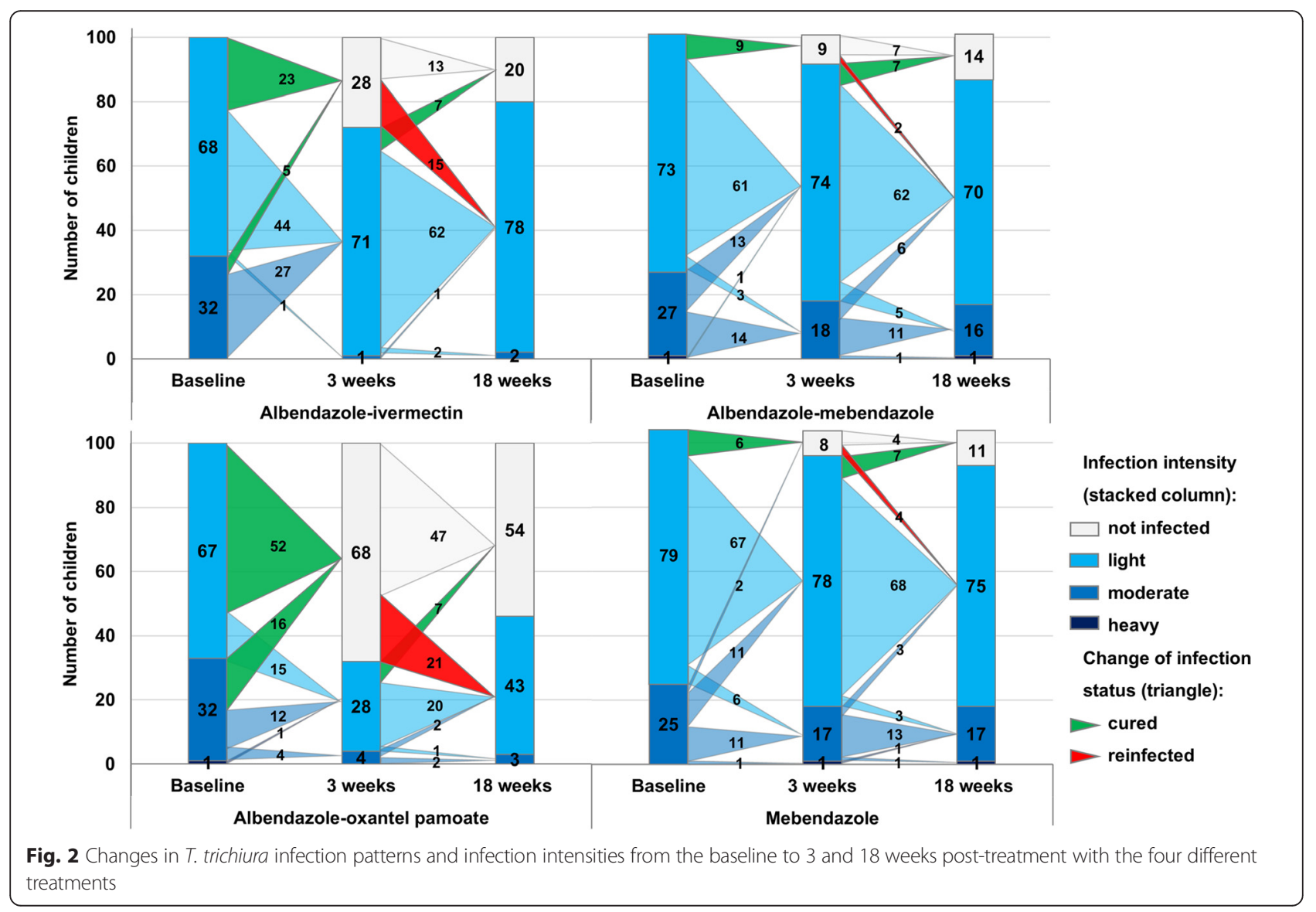


Table 2 Cure rates (CR), extended CRs egg-reduction rates (ERR), extended ERRs and reinfection data for the four different treatments against A. lumbricoides infections. Results of baseline and 3 weeks follow-up have been reported elsewhere [13]

\begin{tabular}{|c|c|c|c|c|c|}
\hline \multicolumn{6}{|l|}{ Ascaris lumbricoides } \\
\hline & $\begin{array}{l}\text { Weeks post- } \\
\text { treatment }\end{array}$ & $\begin{array}{l}\text { Albendazole - ivermectin } \\
(n=100)\end{array}$ & $\begin{array}{l}\text { Albendazole - mebendazole } \\
(n=101)\end{array}$ & $\begin{array}{l}\text { Albendazole - oxantel } \\
\text { pamoate }(n=100)\end{array}$ & $\begin{array}{l}\text { Mebendazole } \\
(n=104)\end{array}$ \\
\hline $\begin{array}{l}\text { Children positive before } \\
\text { treatment (\%) }\end{array}$ & & $46(46.0)$ & $36(35.6)$ & $44(44.0)$ & $43(41.3)$ \\
\hline $\begin{array}{l}\text { No. of children cured } \\
(\mathrm{CR}, 95 \% \mathrm{Cl})\end{array}$ & 3 weeks & $\begin{array}{l}45 \\
(97.8,88.5-99.9)\end{array}$ & $\begin{array}{l}36 \\
(100,90.3-100.0)\end{array}$ & $\begin{array}{l}43 \\
(97.7,88.0-99.9)\end{array}$ & $\begin{array}{l}41 \\
(95.4,84.2-99.4)\end{array}$ \\
\hline $\begin{array}{l}\text { No. of children negative } \\
\text { (extended CR, } 95 \% \mathrm{Cl} \text { ) }\end{array}$ & 18 weeks & $\begin{array}{l}32 \\
(69.6,54.2-82.3)\end{array}$ & $\begin{array}{l}25 \\
(69.4,51.9-83.7)\end{array}$ & $\begin{array}{l}27 \\
(61.4,45.5-75.6)\end{array}$ & $\begin{array}{l}26 \\
(60.5,44.4-75.0)\end{array}$ \\
\hline \multirow[t]{3}{*}{ Geometric mean: EPG } & Baseline & $2,385.8$ & $1,195.3$ & $1,503.4$ & $1,095.2$ \\
\hline & 3 weeks & 0.1 & 0.0 & 0.2 & 0.4 \\
\hline & 18 weeks & 6.9 & 9.1 & 12.5 & 10.6 \\
\hline ERR $(95 \%$ Cl) & 3 weeks & $\begin{array}{l}99.9 \\
(99.9-100.0)\end{array}$ & $100(-)$ & $\begin{array}{l}99.9 \\
(99.9-100)\end{array}$ & $\begin{array}{l}99.9 \\
(99.8-100)\end{array}$ \\
\hline Extended ERR (95\% CI) & 18 weeks & $\begin{array}{l}99.7 \\
(99.1-99.9)\end{array}$ & $\begin{array}{l}99.2 \\
(97.5-99.8)^{\mathrm{a}}\end{array}$ & $\begin{array}{l}99.2 \\
(97.1-99.8)^{a}\end{array}$ & $\begin{array}{l}99.0 \\
(97.7-99.6)^{a}\end{array}$ \\
\hline \multirow[t]{3}{*}{$\begin{array}{l}\text { No. of children positive } \\
\text { (prevalence, } 95 \% \mathrm{Cl} \text { ) }\end{array}$} & Baseline & $\begin{array}{l}46 \\
(46.0,36.1-55.9)\end{array}$ & $\begin{array}{l}36 \\
(35.6,26.1-45.1)\end{array}$ & $\begin{array}{l}44 \\
(44.0,34.1-53.9)\end{array}$ & $\begin{array}{l}43 \\
(41.3,31.7-51.0)\end{array}$ \\
\hline & 3 weeks & $\begin{array}{l}1 \\
(1.0,-1.0-3.0)\end{array}$ & $\begin{array}{l}2 \\
(2.0,-0.8-4.7)\end{array}$ & $\begin{array}{l}3 \\
(3.0,-0.4-6.4)\end{array}$ & $\begin{array}{l}2 \\
(2.0,-0.8-4.6)\end{array}$ \\
\hline & 18 weeks & $\begin{array}{l}24 \\
(24.0,15.5-32.5)\end{array}$ & $\begin{array}{l}28 \\
(27.7,18.8-36.6)\end{array}$ & $\begin{array}{l}33 \\
(33.0,23.6-42.4)\end{array}$ & $\begin{array}{l}33 \\
(31.7,22.6-40.8)\end{array}$ \\
\hline Reinfections (\%, $95 \%$ Cl) & 18 weeks & $\begin{array}{l}14 / 45 \\
(31.1,18.2-46.6)\end{array}$ & $\begin{array}{l}11 / 36 \\
(30.6,16.3-48.1)\end{array}$ & $\begin{array}{l}16 / 43 \\
(37.2,23.0-53.3)\end{array}$ & $\begin{array}{l}16 / 41 \\
(39.0,24.2-55.5)\end{array}$ \\
\hline $\begin{array}{l}\text { New infections (\%, } 95 \% \\
\text { Cl) }\end{array}$ & 18 weeks & $\begin{array}{l}10 / 54 \\
(18.5,9.3-31.4)\end{array}$ & $\begin{array}{l}17 / 63 \\
(27.0,16.6-39.7)\end{array}$ & $\begin{array}{l}15 / 54 \\
(27.8,16.5-41.6)\end{array}$ & $\begin{array}{l}16 / 61 \\
(26.2,15.8-39.1)\end{array}$ \\
\hline
\end{tabular}

Data are $\mathrm{n}(\%, 95 \% \mathrm{Cl})$ unless otherwise indicated. EPG = egg per gram of stool

${ }^{a}$ Significantly lower ERR compared to the 3 weeks ERR (no overlapping confidence interval assumption)

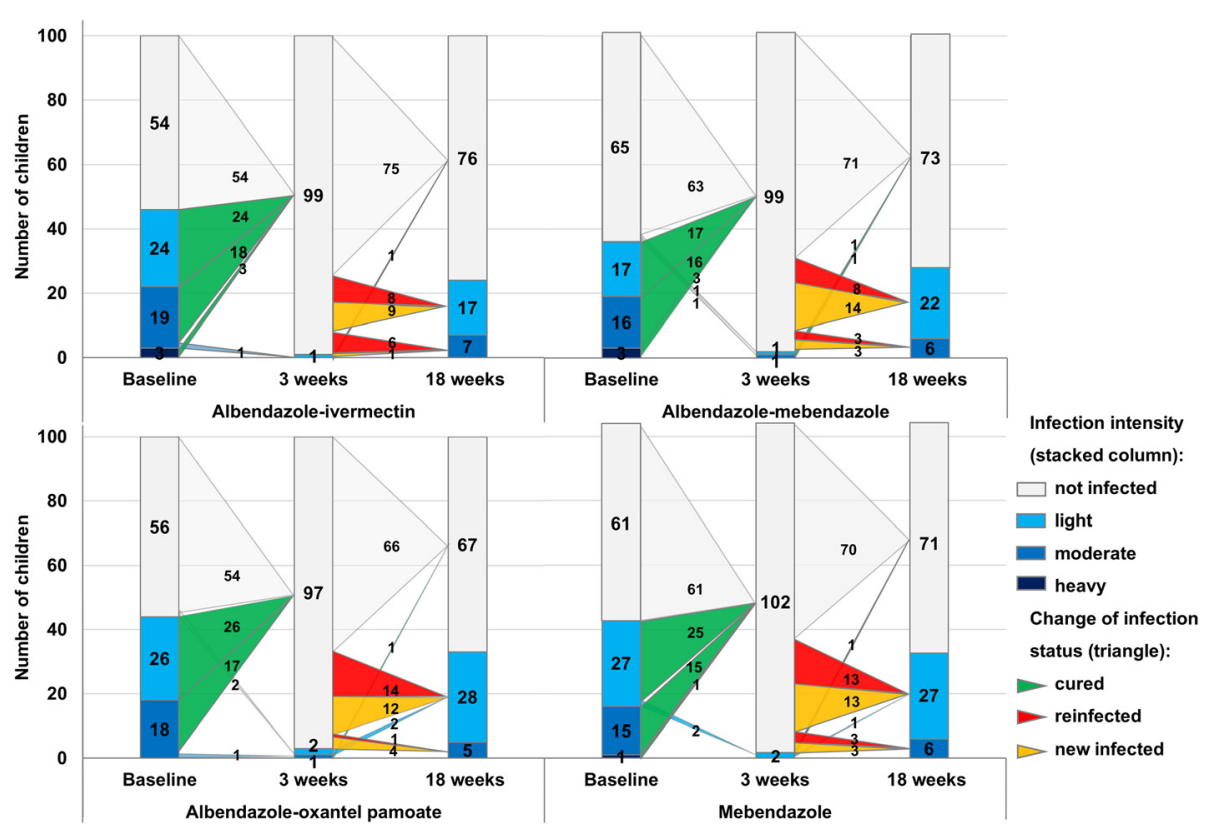

Fig. 3 Changes in A. lumbricoides infection patterns and infection intensities from the baseline to 3 and 18 weeks post-treatment with the four different treatments 
Table 3 Cure rates (CR), extended CRs, egg-reduction rates (ERR), extended ERRs and reinfection data for the four different treatments against hookworms infections. Results of baseline and 3 weeks follow-up have been reported elsewhere [13]

\begin{tabular}{|c|c|c|c|c|c|}
\hline \multicolumn{6}{|l|}{ Hookworms } \\
\hline & $\begin{array}{l}\text { Weeks post- } \\
\text { treatment }\end{array}$ & $\begin{array}{l}\text { Albendazole - ivermectin } \\
(n=100)\end{array}$ & $\begin{array}{l}\text { Albendazole - mebendazole } \\
(n=101)\end{array}$ & $\begin{array}{l}\text { Albendazole - oxantel } \\
\text { pamoate }(n=100)\end{array}$ & $\begin{array}{l}\text { Mebendazole } \\
(n=104)\end{array}$ \\
\hline $\begin{array}{l}\text { Children positive before } \\
\text { treatment (\%) }\end{array}$ & & $38(38.0)$ & $43(42.6)$ & $50(50.0)$ & $41(39.4)$ \\
\hline $\begin{array}{l}\text { No. of children cured } \\
(\mathrm{CR}, 95 \% \mathrm{Cl})\end{array}$ & 3 weeks & $\begin{array}{l}17 \\
(44.7,28.6-61.7)\end{array}$ & $\begin{array}{l}21 \\
(48.8,33.3-64.5, p=0.022)^{*}\end{array}$ & $\begin{array}{l}24 \\
(48.0,33.7-62.6, p=0.023)^{*}\end{array}$ & $\begin{array}{l}10 \\
(24.4,12.4-40.3)\end{array}$ \\
\hline $\begin{array}{l}\text { No. of children negative } \\
\text { (extended CR, } 95 \% \mathrm{Cl} \text { ) }\end{array}$ & 18 weeks & $\begin{array}{l}19 \\
(50.0,33.4-66.6)\end{array}$ & $\begin{array}{l}23 \\
(53.5,37.7-68.8)\end{array}$ & $\begin{array}{l}27 \\
(54.0,39.3-68.2)\end{array}$ & $\begin{array}{l}14 \\
(34.2,20.1-50.6)\end{array}$ \\
\hline \multirow[t]{3}{*}{ Geometric mean: EPG } & Baseline & 113.1 & 139.8 & 87.2 & 80.0 \\
\hline & 3 weeks & 6.1 & 8.3 & 7.1 & 31.8 \\
\hline & 18 weeks & 6.3 & 6.3 & 6.6 & 20.7 \\
\hline ERR $(95 \%$ Cl) & 3 weeks & $\begin{array}{l}94.6 \\
(89.2-97.6)^{a}\end{array}$ & $\begin{array}{l}94.1 \\
(88.7-97.0)^{\mathrm{a}}\end{array}$ & $\begin{array}{l}91.9 \\
(85.0-95.8)^{\mathrm{a}}\end{array}$ & $\begin{array}{l}60.3 \\
(27.8-79.2)\end{array}$ \\
\hline Extended ERR (95 \% Cl) & 18 weeks & $\begin{array}{l}94.4 \\
(88.8-97.5)^{\mathrm{a}}\end{array}$ & $\begin{array}{l}95.5 \\
(91.5-97.8)^{\mathrm{a}}\end{array}$ & $\begin{array}{l}92.4 \\
(85.4-96.3)\end{array}$ & $\begin{array}{l}74.1 \\
(52.8-86.4)\end{array}$ \\
\hline \multirow[t]{3}{*}{$\begin{array}{l}\text { No. of children positive } \\
\text { (prevalence, } 95 \% \text { Cl) }\end{array}$} & Baseline & $\begin{array}{l}38 \\
(38.0,28.3-47.7)\end{array}$ & $\begin{array}{l}43 \\
(42.6,32.8-52.4)\end{array}$ & $\begin{array}{l}50 \\
(50.0,40.0-60.0)\end{array}$ & $\begin{array}{l}41 \\
(39.4,29.9-49.0)\end{array}$ \\
\hline & 3 weeks & $\begin{array}{l}26 \\
(26.0,17.3-34.7)\end{array}$ & $\begin{array}{l}26 \\
(25.7,17.1-34.4)\end{array}$ & $\begin{array}{l}31 \\
(31.0,21.8-40.2)\end{array}$ & $\begin{array}{l}44 \\
(42.3,32.7-52.0)\end{array}$ \\
\hline & 18 weeks & $\begin{array}{l}27 \\
(27.0,18.1-35.9)\end{array}$ & $\begin{array}{l}32 \\
(31.7,22.5-40.9)\end{array}$ & $\begin{array}{l}34 \\
(34.0,24.6-43.4)\end{array}$ & $\begin{array}{l}39 \\
(37.5,28.0-47.0)\end{array}$ \\
\hline $\begin{array}{l}\text { Reinfections } \\
(\%, 95 \% \mathrm{Cl})\end{array}$ & 18 weeks & $\begin{array}{l}5 / 17 \\
(29.4,10.3-56.0)\end{array}$ & $\begin{array}{l}4 / 21 \\
(19.0, .4-41.9)\end{array}$ & $\begin{array}{l}6 / 24 \\
(25.0,9.8-46.7)\end{array}$ & $\begin{array}{l}3 / 10 \\
(30.0,6.7-65.4)\end{array}$ \\
\hline $\begin{array}{l}\text { New infections } \\
(\%, 95 \% \mathrm{Cl})\end{array}$ & 18 weeks & $\begin{array}{l}6 / 57 \\
(10.5,4.0-21.5)\end{array}$ & $\begin{array}{l}9 / 54 \\
(16.7,7.9-29.3)\end{array}$ & $\begin{array}{l}8 / 45 \\
(17.8,8.0-32.1)\end{array}$ & $\begin{array}{l}6 / 50 \\
(12.0,4.5-24.3)\end{array}$ \\
\hline
\end{tabular}

Data are $\mathrm{n}(\%, 95 \% \mathrm{Cl})$ unless otherwise indicated. EPG = egg per gram of stool

* Significantly higher CR compared to mebendazole ( $P$-values derived from logistic regression)

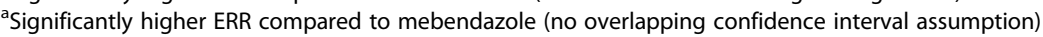

time point albendazole-ivermectin $(94.4 \%$; 88.8-97.5) and albendazole-mebendazole (95.5\%; 91.5-97.8), achieved significantly higher ERRs in comparison to mebendazole (74.1\%; 52.8-86.4). The arithmetic ERRs showed comparable results (Additional file 1: Table S1).

Eighteen weeks post-treatment 18 out of $72(25.0 \%$; 15.5-36.6) children were reinfected with hookworms. All infections were of mild intensity (Table 3, Fig. 4). In total, 29 out of 206 children (14.1\%, CI 9.6-19.6) had acquired a new infection, ranging from $10.5 \%$ (albendazoleivermectin) to $17.8 \%$ (albendazole-oxantel pamoate).

\section{Discussion}

In preventive chemotherapy control programs albendazole and mebendazole are the treatment of choice against infections with all three STHs, yet both reveal a poor efficacy against $T$. trichiura [6]. In the recent past, oxantel pamoate has emerged as frontrunner for the treatment of infections with T. trichiura $[13,19,20]$. In more detail, in our recent studies albendazole-oxantel pamoate revealed good CRs and high ERRs, while mebendazole achieved CRs of $11.8 \%$ [19] and 8.4 \% [13] against $T$. trichiura infection. This low efficacy of mebendazole in the Pemba setting might be due to the occurrence of drug resistance, although molecular studies were not carried out to demonstrate it. In this scenario that is common also to other STH endemic areas, the need of new drug combinations in order to expand the armamentarium of treatments available for preventive chemotherapy strategy is of utmost importance [21].

In addition, albendazole-oxantel pamoate achieved a high reduction of moderate $T$. trichiura infections (persisting at 18 weeks post-treatment) in contrast to mebendazole. Note that, the goal of preventive chemotherapy is to reduce the morbidity from STH in pre- and school-aged children, by decreasing moderate and heavy infection intensities to a level below $1 \%$ [22]. The combination albendazole-oxantel pamoate might contribute to achieve this goal.

Infections after treatment re-appear fast, particularly for A. lumbricoides and hence have a huge impact on the success of preventive chemotherapy [9]. This study presents detailed insights about the impact of drug combinations including the effective oxantel pamoate combination on the reinfection dynamics of the three STHs in a highly endemic area on Pemba Island, Tanzania. Earlier studies on reinfection struggled with the low $\mathrm{CR}$ 


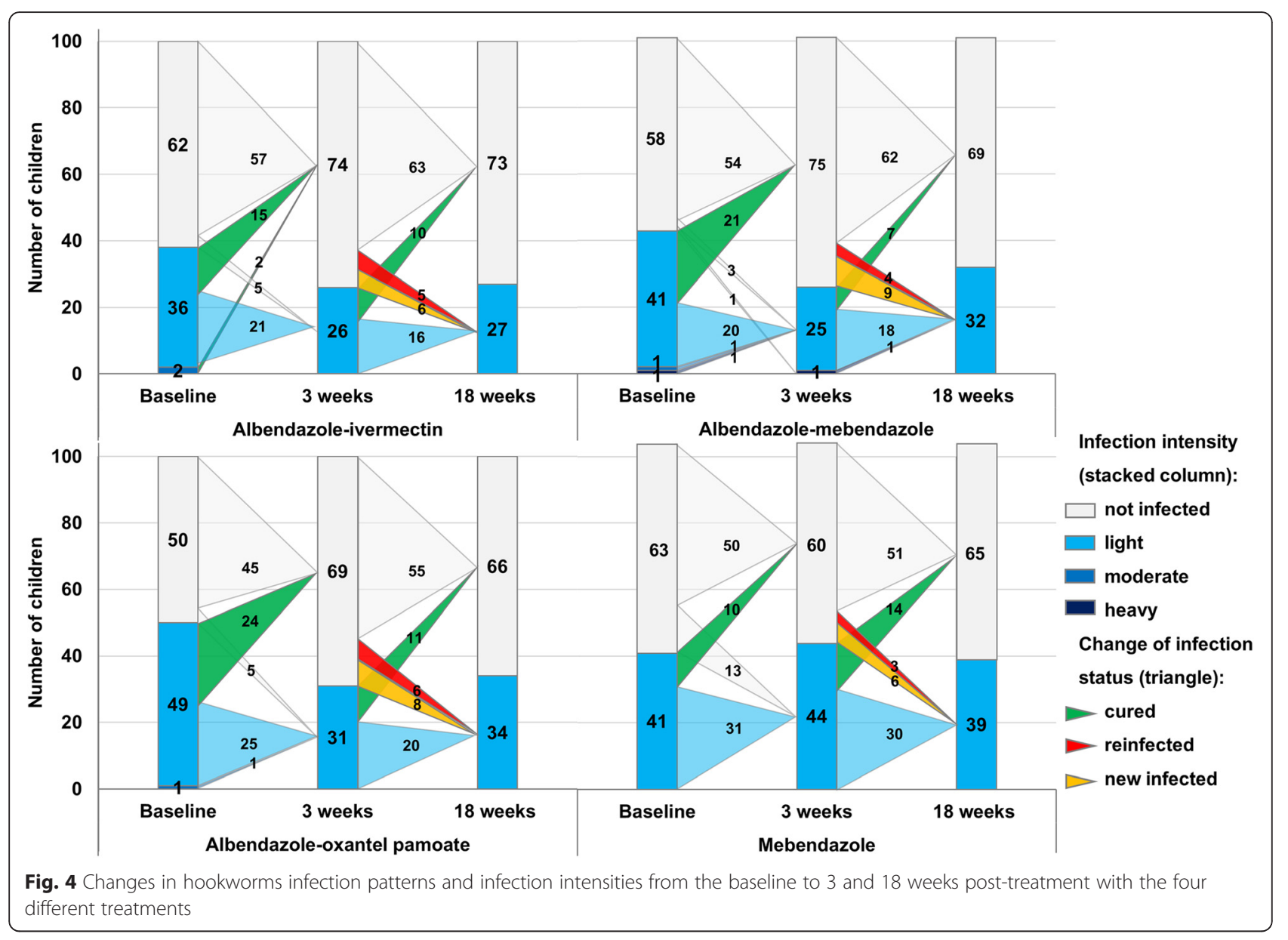

of the standard drugs against T. trichiura which complicated drawing sound conclusions against this helminth species $[9,23]$.

Previous studies on reinfection mainly described the reacquired level of infection after treatment, in comparison to the pre-treatment level and presented the prevalence risk ratio $[9,24,25]$. With the focus only on prevalence before and after treatment, new infections are falsely considered as reinfection. Furthermore, prevalence risk ratios are strongly influenced by the achieved CRs of the treatments. Hence, in this study we distinguish and present both; reinfections rates (positive children at baseline, negative at the 3 week examination point and positive 18 weeks after treatment) and new infections (children with an infection exclusively 18 weeks post-treatment). Note that, children negative at baseline and positive 3 weeks later, which was observed for $A$. lumbricoides and hookworms, were not considered as new infections. We assume, that these children either harboured a non-patent infection or were wrongly diagnosed as negative at baseline [26]. We are confident that our differentiation between reinfections and new infections holds true given that the majority of $A$. lumbricoides and hookworm infections were of moderate intensities at baseline. However, obviously the low sensitivity of the Kato-Katz technique mainly for light infection intensities [26-28] reflects a general limitation of our study. Please note that in the present study four slides were examined by Kato-Katz. However, even when examining multiple thick smears the Kato-Katz method only reaches moderate sensitivity [29]. Therefore our results (i.e. re-infection, new infection) have to be interpreted with caution.

Earlier studies on reinfection with $T$. trichiura reported prevalence to pre-treatment level between 6 and 12 months $[9-11,24,30]$. In our study, the overall reinfection rate 18 weeks post-treatment for $T$. trichiura was $37.2 \%$, which is comparable to the 3 month post treatment prevalence risk ratio of $36.0 \%$ reported by Sinniah [31] and $39.7 \%$ by Al-Mekhlafi et al. [24]. A similar reinfection rate was observed for $A$. lumbricoides (34.6\%), which is in agreement with the 3 month posttreatment data of Jia et al. [9]. On the other hand, Yap et al. [30] documented a higher reinfection rate 4 months after treatment. Additionally, $58(25 \%)$ of the children negative at baseline acquired a new $A$. lumbricoides infection 18 weeks post-treatment. Interestingly, 24 children 
(6.0 \%) who were negative 3 weeks post-treatment harboured already a moderate infection 18 weeks posttreatment, indicating the fast reinfection potential of A. lumbricoides [22].

The three drug combinations cured nearly half of the hookworm-infected children 3 weeks post-treatment, while as expected mebendazole achieved only low CRs [32-35]. Surprisingly, the extended CRs and ERRs among all treatment arms (except the ERR from albendazole-ivermectin) increased at the second compared to the first follow-up. For example, in the mebendazole group, 14 children identified as hookworm-positive 3 weeks post-treatment were negative at the second follow up. This finding is most likely due to a diagnostic issue, i.e. the low sensitivity of Kato-Katz for low egg-counts [36] and a delayed reading of the microscope slides $[15,37]$, which could have led to fluctuations of Kato-Katz results. Overall, the reinfection rate was slower and less new infections with hookworms were observed compared to $A$. lumbricoides and $T$. trichiura, which is in agreement with other studies [9].

\section{Conclusions}

In conclusion, our study has reconfirmed the excellent efficacy of an albendazole-oxantel pamoate combination against $T$. trichiura infections. This combination could become a key element in controlling STH infections, especially in highly endemic settings. Further trials, should evaluate reinfection rates with oxantel pamoate six and 12 month after treatment and ideally after several rounds of treatment.

The moderate reinfection rate observed for $T$. trichiura and A. lumbricoides is worrying. This finding supports the necessity of an integrated control approaches including regular treatment, improved sanitation and health education [38-41], in order to reduce the burden of STH infections.

\section{Additional file}

Additional file 1: Table S1. Arithmetic mean egg per gram (EPG), egg-reduction rates (ERR) and extended ERRs for the four different treatments against $T$. trichiura, A. lumbricoides and hookworms infections. (DOCX $17 \mathrm{~kb}$ )

\section{Abbreviations}

AM: arithmetic mean; CR: cure rate; DALYs: disability-adjusted life years; ERR: egg-reduction rate; GM: geometric mean; STH: soil-transmitted helminth; WHO: World Health Organisation.

\section{Competing interests}

The authors declare that they have no competing interests.

\section{Authors' contributions}

BS, MA, JHa and JK designed the study. BS, WM, SMAI, SMAm and JK implemented the study. BS, WM, JHa and JK analysed and interpreted the data. BS, WM and JK wrote the first draft of the report, and MA and JHa reviewed it. All authors read and approved the final manuscript.

\section{Acknowledgements}

We would like to acknowledge the participating of the school children and their parents. We give thanks to the teacher and headmasters from Mchangamdogo and Shungi schools for their support, Tracy Glass (Swiss TPH) for the randomisation process; and the Public Health Laboratory - Ivo de Carneri's team for the outstanding work in the field and the laboratory. We are grateful to the Swiss National Science Foundation (no. 320030_14930/1) for financial support.

\section{Author details}

${ }^{1}$ Department of Medical Parasitology and Infection Biology, Swiss Tropical and Public Health Institute, Basel, Switzerland. '2University of Basel, Basel, Switzerland. ${ }^{3}$ Laboratory Division, Public Health Laboratory-Ivo de Carneri, Chake Chake, Tanzania. ${ }^{4}$ Ivo de Carneri Foundation, Milan, Italy. ${ }^{5}$ Department of Epidemiology and Public Health, Swiss Tropical and Public Health Institute, Basel, Switzerland.

Received: 30 December 2015 Accepted: 24 February 2016

Published online: 02 March 2016

\section{References}

1. Pullan RL, Smith JL, Jasrasaria R, Brooker SJ. Global numbers of infection and disease burden of soil transmitted helminth infections in 2010. Parasit Vectors. 2014;7:37

2. Bethony J, Brooker S, Albonico M, Geiger SM, Loukas A, Diemert D, Hotez PJ. Soil-transmitted helminth infections: ascariasis, trichuriasis, and hookworm. Lancet. 2006:367(9521):1521-32.

3. Campbell SJ, Savage GB, Gray DJ, Atkinson JA, Soares Magalhães RJ, Nery SV, McCarthy JS, Velleman Y, Wicken JH, Traub RJ, Williams GM, Andrews RM, Clements AC. Water, Sanitation, and Hygiene (WASH): A critical component for sustainable soil-transmitted helminth and schistosomiasis control. PLOS Negl Trop Dis. 2014;8(4):e2651.

4. Hotez P, Raff S, Fenwick A, Richards Jr F, Molyneux DH. Recent progress in integrated neglected tropical disease control. Trends Parasitol. 2007;23(11):511-4.

5. WHO. Accelerating work to overcome the global impact of neglected tropical diseases: a roadmap for implementation. Geneva: World Health Organization; 2006.

6. Keiser J, Utzinger J. Efficacy of current drugs against soil-transmitted helminth infections: systematic review and meta-analysis. JAMA. 2008; 299(16):1937-48.

7. Dayan AD. Albendazole, mebendazole and praziquantel. Review of nonclinical toxicity and pharmacokinetics. Acta Trop. 2003;86(2-3):141-59.

8. Lacey E. Mode of action of benzimidazoles. Parasitol Today. 1990;6(4):112-15.

9. Jia TW, Melville S, Utzinger J, King CH, Zhou XN. Soil-transmitted helminth reinfection after drug treatment: a systematic review and meta-analysis. PLoS Negl Trop Dis. 2012;6(5):e1621.

10. Appleton CC, Mosala TI, Levin J, Olsen A. Geohelminth infection and reinfection after chemotherapy among slum-dwelling children in Durban, South Africa. Ann Trop Med Parasitol. 2009;103(3):249-61.

11. Albonico M, Smith PG, Ercole E, Hall A, Chwaya HM, Alawi KS, Savioli L. Rate of reinfection with intestinal nematodes after treatment of children with mebendazole or albendazole in a highly endemic area. Trans R Soc Trop Med Hyg. 1995;89(5):538-41.

12. Levecke B, Mekonnen Z, Albonico M, Vercruysse J. The impact of baseline faecal egg counts on the efficacy of single-dose albendazole against Trichuris trichiura. Trans R Soc Trop Med Hyg. 2012;106(2):128-30.

13. Speich B, Ali SM, Ame SM, Bogoch II, Alles R, Huwyler J, Albonico M, Hattendorf J, Utzinger J, Keiser J. Efficacy and safety of albendazole plus ivermectin, albendazole plus mebendazole, albendazole plus oxantel pamoate, and mebendazole alone against Trichuris trichiura and concomitant soil-transmitted helminth infections: a four-arm, randomised controlled trial. Lancet Infect Dis. 2015;15(3):277-84.

14. Katz N, Chaves A, Pellegrino J. A simple device for quantitative stool thicksmear technique in schistosomiasis mansoni. Rev Inst Med Trop São Paulo. 1972;14(6):397-400.

15. Martin LK, Beaver PC. Evaluation of Kato thick-smear technique for quantitative diagnosis of helminth infections. Am J Trop Med Hyg. 1968;17(3):382-91.

16. Speich B, Ali SM, Ame SM, Albonico M, Utzinger J, Keiser J. Quality control in the diagnosis of Trichuris trichiura and Ascaris lumbricoides using the Kato-Katz technique: experience from three randomised controlled trials. Parasit Vectors. 2015;8:82. 
17. Albonico M, Crompton DW, Savioli L. Control strategies for human intestinal nematode infections. Adv Parasitol. 1999;42:277-341.

18. Montresor A, Crompton D, Hall A, Bundy D, Savioli L. Guidelines for the evaluation of soil-transmitted helminthiasis and schistosomiasis at community level. Geneva: World Health Organization; 1998.

19. Speich B, Ame SM, Ali SM, Alles R, Huwyler J, Hattendorf J, Utzinger J, Albonico M, Keiser J. Oxantel pamoate-albendazole for Trichuris trichiura infection. N Engl J Med. 2014;370(7):610-20.

20. Moser W, Ali SM, Ame SM, Speich B, Puchkov M, Huwyler J, Albonico M, Hattendorf J, Keiser J: Efficacy and safety of oxantel pamoate in school-aged children infected with Trichuris trichiura on Pemba Island, Tanzania: a parallel, randomised, controlled, dose-ranging study. Lancet Infect Dis. 2015. doi: 10.1016/S1473-3099(15)00271-6

21. Savioli L. Preventive anthelmintic chemotherapy-expanding the armamentarium. N Engl J Med. 2014;370(7):665-6.

22. WHO. Soil-Transmitted Helminthiasis: Eliminating soil-transmitted helminthiasis as a public health problem in children. Progress Report 2001-2010 and Strategic Plan 2011-2020. Geneva: World Health Organization; 2012.

23. Saathoff E, Olsen A, Kvalsvig JD, Appleton CC. Patterns of geohelminth infection, impact of albendazole treatment and re-infection after treatment in schoolchildren from rural KwaZulu-Natal/South-Africa. BMC Infect Dis. 2004:4:27.

24. Hesham Al-Mekhlafi M, Surin J, Atiya AS, Ariffin WA, Mohammed Mahdy AK, Che Abdullah H. Pattern and predictors of soil-transmitted helminth reinfection among aboriginal schoolchildren in rural Peninsular Malaysia. Acta Trop. 2008;107(2):200-4.

25. Olsen A, Thiong'o FW, Ouma JH, Mwaniki D, Magnussen P, Michaelsen KF, Friis $\mathrm{H}$, Geissler PW. Effects of multimicronutrient supplementation on helminth reinfection: a randomized, controlled trial in Kenyan schoolchildren. Trans R Soc Trop Med Hyg. 2003;97(1):109-14.

26. Tarafder MR, Carabin H, Joseph L, Balolong Jr E, Olveda R, McGarvey ST. Estimating the sensitivity and specificity of Kato-Katz stool examination technique for detection of hookworms, Ascaris lumbricoides and Trichuris trichiura infections in humans in the absence of a "gold standard'. Int J Parasitol. 2010;40(4):399-404.

27. Glinz D, Silué KD, Knopp S, Lohourignon LK, Yao KP, Steinmann P, Rinaldi L, Cringoli G, N'Goran EK, Utzinger J. Comparing diagnostic accuracy of KatoKatz, Koga agar plate, ether-concentration, and FLOTAC for Schistosoma mansoni and soil-transmitted helminths. PLoS Negl Trop Dis. 2010;4(7):e754.

28. Knopp S, Mgeni AF, Khamis IS, Steinmann P, Stothard JR, Rollinson D, Marti H, Utzinger J. Diagnosis of soil-transmitted helminths in the era of preventive chemotherapy: effect of multiple stool sampling and use of different diagnostic techniques. PLoS Negl Trop Dis. 2008;2(11):e331.

29. Knopp S, Rinaldi L, Khamis IS, Stothard JR, Rollinson D, Maurelli MP, Steinmann P, Marti $\mathrm{H}$, Cringoli $\mathrm{G}$, Utzinger J. A single FLOTAC is more sensitive than triplicate Kato-Katz for the diagnosis of low-intensity soil-transmitted helminth infections. Trans R Soc Trop Med Hyg. 2009;103(4):347-54.

30. Yap P, Du ZW, Wu FW, Jiang JY, Chen R, Zhou XN, Hattendorf J, Utzinger J, Steinmann P. Rapid re-infection with soil-transmitted helminths after tripledose albendazole treatment of school-aged children in Yunnan, People's Republic of China. Am J Trop Med Hyg. 2013;89(1):23-31.

31. Sinniah B. Intestinal protozoan and helminth infections and control of soil-transmitted helminths in Malay school children. Public Health. 1984; 98(3):152-6.

32. Steinmann P, Utzinger J, Du Z-W, Jiang J-Y, Chen J-X, Hattendorf J, Zhou H, Zhou X-N. Efficacy of single-dose and triple-dose albendazole and mebendazole against soil-transmitted helminths and Taenia spp.: a randomized controlled trial. PLOS ONE. 2011;6(9):e25003.

33. Soukhathammavong PA, Sayasone S, Phongluxa K, Xayaseng V, Utzinger J, Vounatsou P, Hatz C, Akkhavong K, Keiser J, Odermatt P. Low efficacy of singledose albendazole and mebendazole against hookworm and effect on concomitant helminth infection in Lao PDR. PLoS Negl Trop Dis. 2012;6(1):e1417.

34. Levecke B, Montresor A, Albonico M, Ame SM, Behnke JM, Bethony JM, Noumedem CD, Engels D, Guillard B, Kotze AC, Krolewiecki AJ, McCarthy JS, Mekonnen Z, Periago MV, Sopheak H, Tchuem-Tchuenté LA, Duong TT, Huong NT, Zeynudin A, Vercruysse J. Assessment of anthelmintic efficacy of mebendazole in school children in six countries where soil-transmitted helminths are endemic. PLoS Negl Trop Dis. 2014;8(10):e3204.

35. Flohr C, Tuyen LN, Lewis S, Minh TT, Campbell J, Britton J, Williams H, Hien TT, Farrar J, Quinnell RJ. Low efficacy of mebendazole against hookworm in Vietnam: two randomized controlled trials. Am J Trop Med Hyg. 2007;76(4): 732-6.
36. Booth M, Vounatsou P, N'goran EK, Tanner M, Utzinger J. The influence of sampling effort and the performance of the Kato-Katz technique in diagnosing Schistosoma mansoni and hookworm co-infections in rural Côte d'Ivoire. Parasitology. 2003;127(Pt 6):525-31.

37. Barda B, Albonico M, lanniello D, Ame SM, Keiser J, Speich B, Rinaldi L, Cringoli G, Burioni R, Montresor A, Utzinger J. How long can stool samples be fixed for an accurate diagnosis of soil-transmitted helminth infection using Mini-FLOTAC? PLoS Negl Trop Dis. 2015;9(4):e0003698.

38. Ziegelbauer K, Speich B, Mäusezahl D, Bos R, Keiser J, Utzinger J. Effect of sanitation on soil-transmitted helminth infection: systematic review and meta-analysis. PLoS Med. 2012;9(1):e1001162.

39. Gyorkos TW, Maheu-Giroux M, Blouin B, Casapia M. Impact of health education on soil-transmitted helminth infections in schoolchildren of the Peruvian Amazon: a cluster-randomized controlled Trial. PLoS Negl Trop Dis. 2013;7(9):e2397.

40. Bieri FA, Gray DJ, Williams GM, Raso G, Li YS, Yuan L, He Y, Li RS, Guo FY, Li SM, McManus DP. Health-education package to prevent worm infections in Chinese schoolchildren. N Engl J Med. 2013;368(17):1603-12.

41. Asaolu SO, Ofoezie IE. The role of health education and sanitation in the control of helminth infections. Acta Trop. 2003;86(2-3):283-94.

\section{Submit your next manuscript to BioMed Central and we will help you at every step:}

- We accept pre-submission inquiries

- Our selector tool helps you to find the most relevant journal

- We provide round the clock customer support

- Convenient online submission

- Thorough peer review

- Inclusion in PubMed and all major indexing services

- Maximum visibility for your research

Submit your manuscript at www.biomedcentral.com/submit

) Biomed Central 